\title{
Theoretical considerations on a thermodynamic mode of muscle action
}

Citation for published version (APA):

Hemker, H. C., \& Hermens, W. TH. (1971). Theoretical considerations on a thermodynamic mode of muscle action. Cardiovascular Research, 5(Suppl. 1), 84-86. https://doi.org/10.1093/cvr/5.supp1.84

Document status and date:

Published: 01/01/1971

DOI:

10.1093/cvr/5.supp1.84

Document Version:

Other version

\section{Please check the document version of this publication:}

- A submitted manuscript is the version of the article upon submission and before peer-review. There can be important differences between the submitted version and the official published version of record.

People interested in the research are advised to contact the author for the final version of the publication, or visit the DOI to the publisher's website.

- The final author version and the galley proof are versions of the publication after peer review.

- The final published version features the final layout of the paper including the volume, issue and page numbers.

Link to publication

\footnotetext{
General rights rights.

- You may freely distribute the URL identifying the publication in the public portal. please follow below link for the End User Agreement:

www.umlib.nl/taverne-license

Take down policy

If you believe that this document breaches copyright please contact us at:

repository@maastrichtuniversity.nl

providing details and we will investigate your claim.
}

Copyright and moral rights for the publications made accessible in the public portal are retained by the authors and/or other copyright owners and it is a condition of accessing publications that users recognise and abide by the legal requirements associated with these

- Users may download and print one copy of any publication from the public portal for the purpose of private study or research.

- You may not further distribute the material or use it for any profit-making activity or commercial gain

If the publication is distributed under the terms of Article $25 \mathrm{fa}$ of the Dutch Copyright Act, indicated by the "Taverne" license above, 


\title{
THEORETICAL CONSIDERATIONS ON A THERMODYNAMIC MODEL OF MUSCLE ACTION
}

\author{
BY \\ H. C. HEMKER and W. TH. HERMENS
}

Reprinted from Cardiovascular Research

Supplement, No. 1, pages 84-86, July 1971

COPYRIGHT (C) 1971

CARDiOVASCULAR RESEARCH

ALL RIGHTS OF REPRODUCTION OF THIS REPRINT ARE RESERVED IN ALI COUNTRIES OF THE WORLD

LONDON

BRITISH MEDICAL ASSOCIATION

TAVISTOCK SQUARE, W.C.1 


\title{
Theoretical considerations on a thermodynamic model of muscle action
}

\author{
H. C. Hemker and W. Th. Hermens \\ From the Laboratory of Cardiobiochemistry, University Hospital, Leiden, Holland
}

The usual models of muscle action come in two types: the morphological and biochemical models try to explain how muscle proteins interact so as to cause contraction, the physiological models explain the data on contractility and elasticity in terms of coupled contractile and elastic elements.

Both types of models are not meant to give insight in the interrelations between chemical and mechanical processes - at least not on a quantitative basis. Yet such interrelations are of interest for the study of the contractility of muscle, because the ratio of mechanical energy output to chemical energy input defines the efficiency of the muscle and because the influence of various external parameters on this efficiency is of interest both in experimental and clinical situations.

It is the purpose of this communication to present a thermodynamic model of muscle action in which such interrelations can be considered. This model is not meant to replace morphological, biochemical, or physiological models. Rather is it our aim not to be in contradiction with any of these, but to focus on properties that are not in the scope of other models.

The simplest model of a chemocontractile machine consists of a cylinder, closed with a piston in which two substances $\mathrm{M}$ and $\mathrm{D}$ are contained that can chemically interconvert that is:

$$
\mathrm{M} \rightleftarrows \mathrm{D}
$$

When the partial volume of $\mathrm{D}$ is less than that of $\mathrm{M}$, a shift of the reaction towards the right will cause the volume to decrease and hence the piston to move inwards - for example, under the influence of atmospheric pressure.

Muscle hardly changes its volume upon contraction, but it does change its length. In an isotropic medium, according to Curie's law, changes in chemical composition are unable to influence length without the aid of a mechanical device like a piston. Muscle, however, is anisotropic, so that a direct coupling between length and chemical changes is feasible. In order to describe such changes, we have to postulate a property of the components of the system that influences the total length of the system just as partial volume influences the volume. We called this property partial length $\left(\lambda_{1}\right)$ and defined it as the infinitesimal change of overall length with an infinitesimal addition of the substance under consideration - that is :

$$
\lambda_{\mathrm{m}}=\left(\frac{\partial \mathrm{l}}{\partial \mathbf{M}_{\mathrm{m}}}\right)_{\mathrm{M}_{\mathrm{d}}, \mathrm{P}, \mathrm{T}} \quad \lambda_{\mathrm{d}}=\left(\frac{\partial 1}{\partial \mathbf{M}_{\mathrm{d}}}\right)_{\mathrm{M}_{\mathrm{m}}, \mathrm{P}, \mathrm{T}}
$$

When $\lambda_{d}<\lambda_{m}$ a shift to the right in reaction (a) will cause shortening.

When we assume that the heat content of the system does not change $(\mathrm{dQ}=0)$ and neither does the volume $(\mathrm{dV}=0)$, the change in internal energy of a contractile system in which a reaction occurs is given by:

$$
\mathrm{dU}=\mathrm{fdl}+A \mathrm{~d} \xi
$$

Table of symbols used in this paper

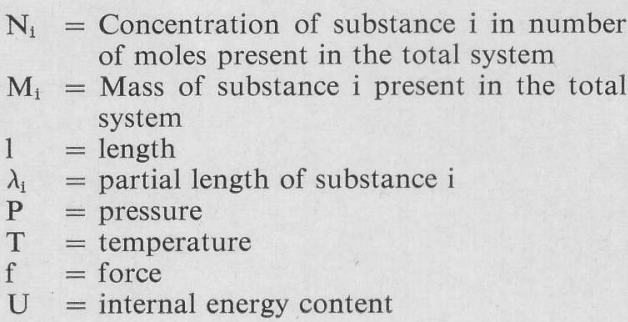

$$
\begin{aligned}
& A=\text { affinity } \\
& \mathrm{m}_{1}=\text { molecular weight of substance } \mathrm{i} \\
& \xi=\text { progress variable of a chemical reaction } \\
& \mathrm{Q}=\text { heat content } \\
& \mathrm{V}=\text { volume } \\
& \mu_{1}=\text { chemical potential of substance } \mathrm{i} \\
& \mathrm{dN}_{1}=\text { change in concentration of substance } \mathrm{i} \text { by } \\
& \mathrm{S} \quad \text { exchange with the environment } \\
& \mathrm{S}
\end{aligned}
$$


where $A=\mathrm{m}_{\mathrm{d}} \mu_{\mathrm{d}}-\mathrm{m}_{\mathrm{m}} \mu_{\mathrm{m}}$ by definition, and $\mathrm{d} \xi=\mathrm{dN}_{\mathrm{d}}=-\mathrm{dN}_{\mathrm{m}}$ by definition. As $\mathrm{dU}$ is a total differential it follows from (2) that

$$
\left(\frac{\partial \mathrm{f}}{\partial \xi}\right)_{1}=\left(\frac{\partial A}{\partial 1}\right)_{\xi}
$$

In equilibrium $A=0$ : as $A$ contains a term dependent upon the concentrations of $\mathrm{M}$ and $\mathrm{D}, A=0$ defines the composition of the system, and therewith its length (all other variables being held constant). It thus follows that

$$
\frac{\partial A}{\partial 1} \neq 0
$$

An externally imposed change in length will cause $A$ to change - that is, to deviate from zero. This means that the reaction will start to proceed, so that $\mathrm{d} \xi \neq 0$. Because of the relationships (3) and (4) a change in force will accompany a change in the progress variable ( $\xi$ ). A change in length thus causes $A$ and $\xi$ as well as $f$ to change. This chemical coupling between force and length means that, for example, computer-simulations of forcevelocity relations using the usual models should account for the fact that, in a chemocontractile system, the characteristic parameters of the contractile and elastic components cannot be varied independently of each other. To a certain extent one could say that contractile and elastic elements are identical.

Apart from the trivial cross-relations mentioned here, of which we will give a few other examples, the irreversible flows in a muscle - as, for example, heat flow - are also coupled (Onsager-relations). For instance there is a cross-effect between changes in chemical reaction velocity and changes in pressure. We are at present studying this subject.

We will now extend our system to obtain a more realistic model of muscle contraction. First we will assume that, instead of one equilibrium reaction $M \rightleftarrows D$, the following reaction scheme is operative:

$$
\begin{aligned}
\mathrm{M}+\mathrm{S} & \rightarrow \mathrm{D}+\mathrm{R} \\
\mathrm{D} & \rightarrow \mathrm{M}
\end{aligned}
$$

We may well ask if and how these reactions are represented in real muscle. $\mathrm{M}$ and $\mathrm{D}$ are thought to be the contractile molecule (or group of molecules) in their relaxed state (M) or contracted (D). S is the energy-yielding molecule (ATP), $\mathrm{R}$ is the breakdown product of S (ADP).

$M$ (and D) represent the actomyosin complex. A more detailed reaction scheme is possible on the basis of the biochemical data available, including the combination of actin with myosin-ATP, etc. Such a scheme would not, however, change the basic conclusion that can be drawn from thermodynamic considerations, and therefore is not within the scope of this article.

It appears sufficient to envisage the muscle as a contractile 'black box' in which chemical reactions occur. The energy comes from a substance $\mathrm{S}$ that enters the 'black box' from its surroundings, $\mathrm{R}$ is a product of the inside activity. A set of two reactions that partly reverse each other, like (b) and (c), is the simplest picture of this activity. Apart from considering two chemical reactions, we will also include the possibility of mass-exchange between our system and its environment. In particular, we will assume the existence of flows of substances $\mathrm{S}$ and $\mathrm{R}$ between the system and its surrounding.

The change in internal energy in this case is given by:

$$
\begin{aligned}
\mathrm{dU}= & \mathrm{TdS}-\mathrm{PdV}+\mathrm{fdl}+A_{1} \mathrm{~d} \xi_{1} \\
& +A_{2} \mathrm{~d} \xi_{2}+\mu_{\mathrm{S}} \widetilde{\mathrm{d}} \mathrm{M}_{\mathrm{S}}+\mu_{\mathrm{R}} \mathrm{dM}_{\mathrm{R}}
\end{aligned}
$$

The entropy change dS is the exchange of heat of our system with the surroundings (dQ) as well as the heat internally produced for example, when an exothermic chemical reaction takes place. The symbol $\sim$ denotes changes that accompany external transport.

We assume

I $d V \approx 0$ - that is, no negligible changes in volume occur

$2 \mathrm{~m}_{\mathrm{S}} \approx \mathrm{m}_{\mathrm{R}}$

$3 d \tilde{N}_{R}=-d \tilde{N}_{S}-$ that is, substance $S$ enters our system at the same rate as $\mathrm{R}$ leaves it. Under these conditions the expression for the internal energy change becomes:

$$
\begin{aligned}
\mathrm{dU}=\mathrm{TdS}+\mathrm{fdl} & +A_{1} \mathrm{~d} \xi_{1} \\
& +A_{2} \mathrm{~d} \xi_{2}+\Delta \mu \tilde{\mathrm{d}} \mathrm{M}_{\mathrm{S}}
\end{aligned}
$$

where

$$
\Delta \mu \equiv \mu_{\mathrm{S}}-\mu_{\mathrm{R}}
$$

From (6) we find the cross-relation

$$
\left(\frac{\partial \mathrm{f}}{\tilde{\partial} \mathrm{M}_{\mathrm{S}}}\right)_{\mathrm{S}, 1, \xi_{1}, \xi_{2}}=\left(\frac{\partial \Delta \mu}{\partial 1}\right)_{\mathrm{S}, \xi_{1}, \xi_{2}, \mathrm{M}_{\mathrm{S}}}
$$

The quantity $\Delta \mu$ defined by (7) determines the net energy-gain by the inflow and outflow of $\mathrm{S}$ and $\mathrm{R}$ respectively. We see from (8) that $\Delta \mu$ changes with length - that is, the metabolic efficiency must change when the muscle is stretched.

One can also prove the following relation to be valid for our system:

$$
-\mathrm{SdT}+\mathrm{VdP}+\mathrm{fdl}-\sum_{\mathbf{i}} \mathrm{M}_{\mathrm{i}} \mathrm{d} \mu_{\mathrm{i}}=0
$$

(Gibbs-Duhem relation), which yields the following cross-relation

$$
\left(\frac{\partial \mathrm{f}}{\partial \mu_{\mathrm{M}}}\right)_{\mathrm{T}, \mathrm{P}, 1, \mu_{\mathrm{R}}, \mu_{\mathrm{S}, \mu_{\mathrm{D}}}}=\left(\frac{\partial \mathrm{M}_{\mathrm{M}}}{\partial 1}\right)_{\mathrm{T}, \mathrm{P}, \mu}
$$


Assuming the exerted force $\mathrm{f}$ stronger with increasing $\mu_{\mathrm{M}}$, we find the Le Chatelierprinciple - for example, an externally imposed stretch would increase the fraction of contractile molecules in the relaxed state $\left(\mathrm{M}_{\mathrm{M}}\right)$.

Introducing the state-parameter

$$
\mathrm{G}=\mathrm{U}-\mathrm{TS}+\mathrm{PV}-\mathrm{f} 1
$$

we find from (5) and (6)

$$
\begin{aligned}
\mathrm{dG}=- & \mathrm{SdT}+\mathrm{VdP}-1 \mathrm{df} \\
& +A_{1} \mathrm{~d} \xi_{1}+A_{2} \mathrm{~d} \xi_{2}+\Delta \tilde{\mu \mathrm{dM}_{\mathrm{S}}}
\end{aligned}
$$

resulting in the cross-relation

$$
\left(\frac{\partial \Delta \mu}{\partial \mathrm{f}}\right)_{\mathrm{T}, \mathrm{P}, \xi_{1}, \xi_{2}, \mathrm{M}_{\mathrm{S}}}=-\left(\frac{\partial 1}{\tilde{\partial} \mathrm{M}_{\mathrm{S}}}\right)_{\mathrm{T}, \mathrm{P}, \mathrm{f}, \dot{\xi}_{1}, \xi_{2}}
$$

So $\Delta \mu$ changes with force as well as with length.

The breakdown of $\mathrm{S}$ in the muscle $\left(\mathrm{d} \xi_{1}\right)$ likewise is coupled to force and length. This is easily derived from the formulae (5) and (II), analogous to the derivation of (9) and (I2).

Finally, we consider a stationary contracted state which means that the chemical reactions (b) and (c) and the external flow balance each other, while the system may still exert a force but does not change its length - that is, the internal energy as well as the length do not change any more. For this case we can derive the relation:

$$
\mathrm{dU}=\mathrm{dQ}+\Delta \mu \tilde{\mathrm{d}} \mathrm{M}_{\mathrm{S}}=0
$$

where we used the assumptions

I no temperature gradient exists within the system,

2 electrical, surface, and viscosity effects are negligible.

The relation (13) shows that in such a stationary state the chemical energy from the conversion $\mathrm{S} \rightarrow \mathrm{R}$ comes out as heat.

It should be remembered that these relations consider a system containing a constant amount of contractile material $\left(\mathrm{M}_{\mathrm{M}}+\mathrm{M}_{\mathrm{D}}\right)$. In muscle, however, the availability of reactive actin will vary with the $\mathrm{Ca}^{++}$ concentration, and the possibility that reactive actin and myosin will interact will change with length, because the zone of overlap between actin and myosin filaments, not considered until now, changes.

In other words: the relations found here hold at constant 'activation' of actin - for example, constant intracellular $\mathrm{Ca}^{++}$concentration - and at a constant overlap of actin and myosin. In order to arrive at a more realistic description, it is therefore necessary to consider the consequences of $\mathbf{M}_{M}+\mathbf{M}_{\mathrm{D}}$ being dependent upon time and upon the amount of overlap. This is at present being investigated. However, the considerations presented above show that the relations between force, velocity, heat, energy consumption, etc., found experimentally cannot be explained on the sole basis of changes in overlap and 'activation' of actin only.

The change in $\Delta \mu$ that occurs with changes in length and force is especially interesting, because it shows that, dependent upon external parameters, a variable fraction of the energy from the reaction $\mathrm{S} \rightarrow \mathrm{R}$ - that is, $\mathrm{ATP} \rightarrow \mathrm{ADP}+\mathrm{P}_{\mathrm{i}}-$ is converted into mechanical energy (the remainder coming out as heat).

\section{Summary}

It is shown that, in a hypothetical contractile element in which the amount of active contractile material does not change (which would be comparable with a constant $\mathrm{Ca}^{++}$concentration and a constant zone of overlap in real muscle), there still exist cross-relations between force and length and reaction velocity and mechanical efficiency. Relationships between these variables, observed experimentally, are thus not to be explained in terms of independent contractile and elastic elements, or changes in zone of overlap only. 